DOI: 10.17707/AgricultForest.61.3.20

\author{
Alireza ESLAMI, \\ Seyed Mohamad Taghi HOSEINI ${ }^{1}$
}

\title{
THE DYNAMICS OF DIFFERENT DEVELOPMENTAL STAGES IN NATURAL ORIENTAL BEECH ( Fagus orientalis LIPSKY) STANDS IN NORTHERN IRAN
}

\begin{abstract}
SUMMARY
Present study was carried out in natural oriental beech stands created by regeneration and without human technical interference, located in one district, compartment 128 (the reserve compartment or untouched)of management plan in Shamoushak of Gorgan in northern Iran, on 2013. After the primary forest tour, 5-hectare sample plots were selected and each were divided into 1-hectare plots $(100 \times 100 \mathrm{~m})$ and also, two transects each with a size of $10 \times 100 \mathrm{~m}\left(1000 \mathrm{~m}^{2}\right)$ were selected and to assess the regeneration, 9 micro sample plots each with a size of $3 \times 3(9 \mathrm{~m} 2)$ were considered inside the transects. A $\% 100$ inventory (full callipering) was done on all of the stand's parameters including diameter at breast height (dbh), snags, height of the trees, natural regeneration, quality of tree trunks and canopy condition. Then, considering the developmental stages and phases defined in reserve forests and adapting these theories with current condition of the studied stand, the results showed that, abundance of the trees in the initial stage has been decreased compared to optimal and decay stages. The highest volume has been in optimal stage and the lowest has been in decay stage. The highest volume of dead and fallen trees has been in decay stage and with opening of the canopy cover in this stage, regeneration is increased. In terms of heights of the trees, in optimal stage, the stand is of single-story type with low height differences and quality of the tree trunks has been increased in this stage. Number increase in the first diameter class in the initial stage implies regeneration of revitalization. Through thinning operations in optimal stage, we can obtain creation of mixed stands with rich and stable structures).
\end{abstract}

Keywords: Oriental Beech, Developmental Stages, Regeneration, Untouched forest, Iran

\section{INTRODUCTION}

Close to nature silviculture method can be the best choice for management of natural stands (Eslami and Sagheb Talebi, 2007); methods based on minimum interference with natural structure and processes in forests. Use of the Close to nature silviculture method not possible without a reliable source and having

\footnotetext{
${ }^{1}$ Alireza Eslami, (Corresponding author: dr_eslami2006@yahoo.com), Department of Agriculture, Rasht Branch, Islamic Azad University, Rasht, IRAN, Seyed Mohamad Taghi Hoseini, Department of Natural Resources and watershed management in Golestan, IRAN

Note: The authors declare that they have no conflicts of interest. Authorship Form signed online.
} 
accurate knowledge about it, in other words, the first step in this method is recognition of the dynamics of these stands in the sequence process (Sefidi et al., 2014). The oriental beech species is one of the valuable species of northern forests of Iran which has a significant role in sequence and developmental cycles of these forests, in a way that in altitude ranges of 700-2000 metres above sea level (m.a.s.l), it is known as one of the climax main species of northern forests (Delfan Abazari, et al., 2007 ). Study of the biodiversity and structure of the forests is one of the most important prerequisites for understanding and managing the forest ecosystems (Motz, et al., 2010). In general, structure of a forest investigates the distribution of characteristics of the trees within the forest ecosystems (Gadow, 2006). Upon arrival of physiological longevity age and death, a tree in the forest falls and creates a gap. The seeds fallen on this gap germinate when the condition is appropriate and the resulted seedlings create the final forests as a result of competing and during various growth stages. All events taking place during this time are along with changes in forest called developmental stages.

Having knowledge about nature of the species is one of the important factors in tending the forest stands (Parhizkar,et al., 2011a). Based on a definition by Korpel (1995), developmental stages are tree main stages including initial, optimal and decay stages with considering the story and habitat conditions in different forests. Among the researchers conducted in field of evaluating the developmental stages of the stands, the studies carried out by Alijani,et al., (2012), Sagheb Talebi,et al., (2003), Eslami,et al., (2007), Akhavan,et al., (2010), Hasani\&Amani (2009) and also, the studies carried out by Korpel (1995), Leibundgut (1993) and Emborg, et al.,(2000) can be mentioned. This research aims at recognition and introduction of different developmental stages in untouched natural oriental beech stands. The results from this study can be used as a pattern for sustainable management in the close to nature silviculture method.

\section{MATERIAL AND METHODS}

The studied area has been located in Jahannama division of Shamoushak management plan, in scope of Department of Natural Resources Gorgan in Northern o fIran. The height range of the studied oriental beech stand is 13502000 (m.a.s.1), the area's slope is between 15 to 30 percents, the general direction is north-western and it has calcareous soil in much of the surface. The studied forest is of pure and mixed broadleaf type, in form of un-even aged stands and the dominant type is oriental beech and hornbeam.

In order to conduct this research in management plan of compartment 128 district one of Shamoushak of Gorganwhich has been selected as the untouched plot since preparation of the early management plans and no scheduled operations has been applied so far in it, was selected. In the next stage, according to definitions presented by Korpel (1995) for developmental stages and phases, by taking several forest tours, some areas in related compartments were identified 
and selected as the research bases. In this regard, 5sample plots 1-hectare squareshaped with a size of $100 \times 100$ were selected and silvicultural characteristics of each tree with diameters more than $7.5 \mathrm{~cm}$, including $\mathrm{dbh}$, height of the trees, cover canopy and tree trunk quality was measured and studied. 2 perpendicular transects in the sample plot with sizes of $10 \times 100$ meters $\left(1000 \mathrm{~m}^{2}\right)$ were selected and in addition to the characteristics studied in the main sample, regeneration condition with 9 micro sample plots each with a size of $3 \times 3 \mathrm{~m}\left(9 \mathrm{~m}^{2}\right)$ in the transact was also evaluated (figure1). All regenerations according to species were measured in two regeneration classes including diameters of 0-2.5 cm and 2.5-7.5 $\mathrm{cm}$. Excel and Spss software were used for data analysis.
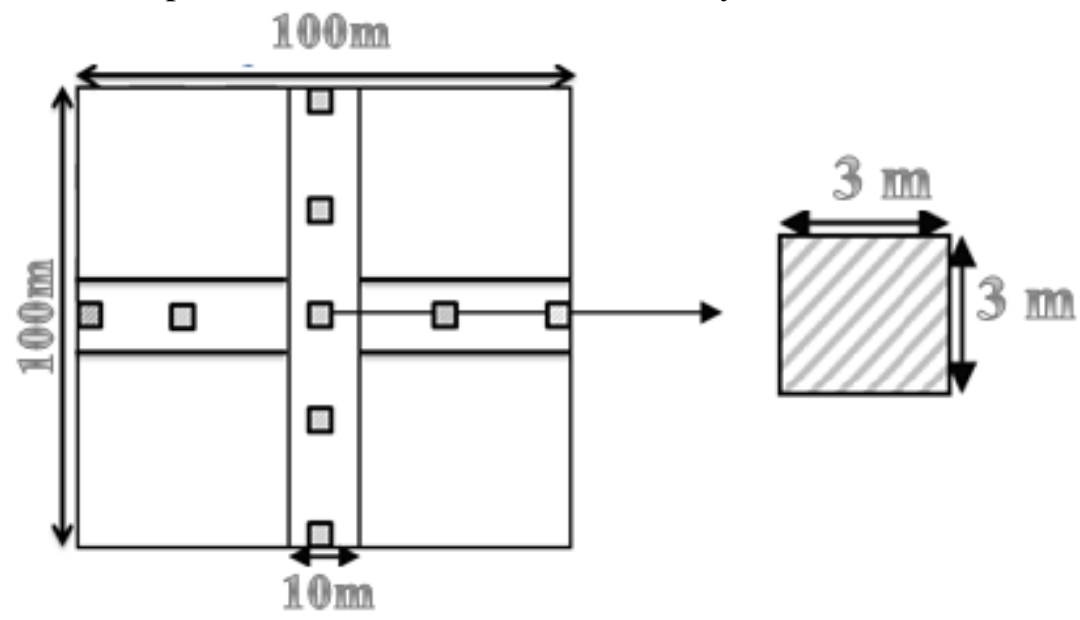

Fig1. Appearance of the one hectare sample plots, condition of the transects and micro plots.

\section{RESULTS}

Study results of general condition of silvicultural characteristics in different developmental stages in the studied stand have been presented in table1.

Table1. General Condition of Silvicultural Characteristics in Different Developmental Stages

\begin{tabular}{lccccc}
\hline $\begin{array}{c}\text { Developmental } \\
\text { Stages }\end{array}$ & $\begin{array}{c}\text { The number } \\
\text { of trees } \\
\text { (N/ha) }\end{array}$ & $\begin{array}{c}\text { The number } \\
\text { of dry and } \\
\text { fallen trees } \\
\text { (N/ha) }\end{array}$ & $\begin{array}{c}\text { The volume } \\
\text { of trees }\left(\mathrm{m}^{3}\right)\end{array}$ & $\begin{array}{c}\text { The volume } \\
\text { of dry and } \\
\text { fallen trees } \\
\left(\mathrm{m}^{3}\right)\end{array}$ & $\begin{array}{c}\text { Regeneration } \\
\text { (N/ha) }\end{array}$ \\
\hline Initial stage & 81 & 3 & 71.82 & 0.8 & 150 \\
Optimal stage & 55 & 2 & 93.19 & 0.45 & 98 \\
Decay stage & 24 & 6 & 30.7 & 5.72 & 51
\end{tabular}

Figure 2 shows that the average number per hectare in the first stage has the highest value and the lowest value belongs to decay stage. 


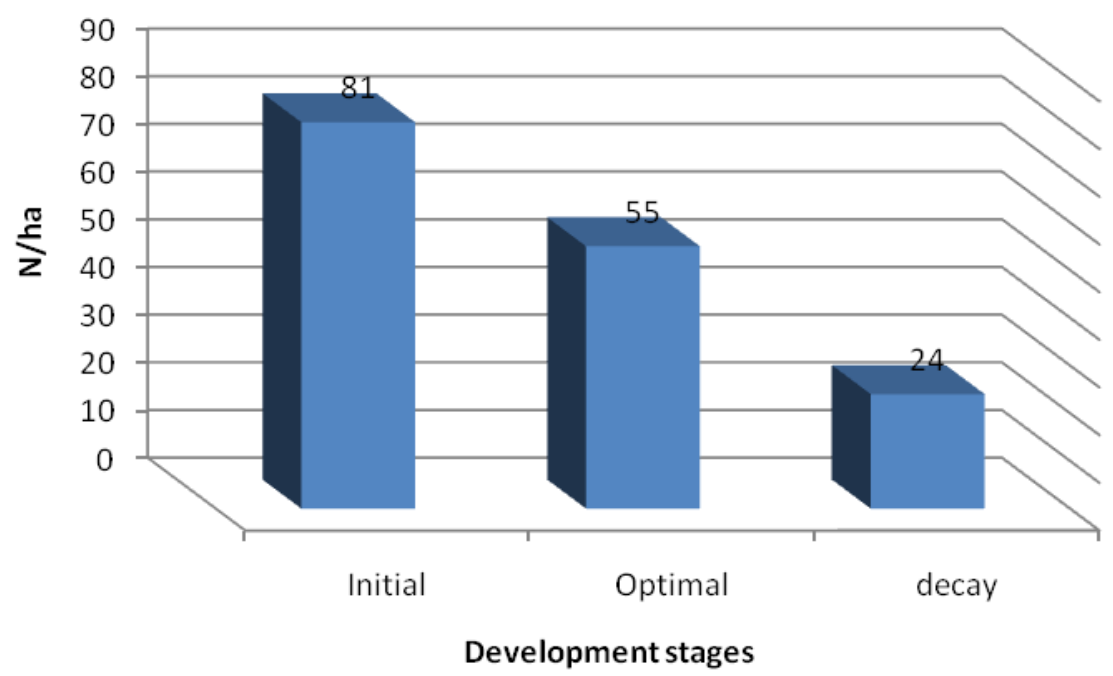

Fig.2. Average Number per Hectare of the Trees According to developmental stages

Figure 3 shows that the number of dead and fallen trees in decay stage is very high.

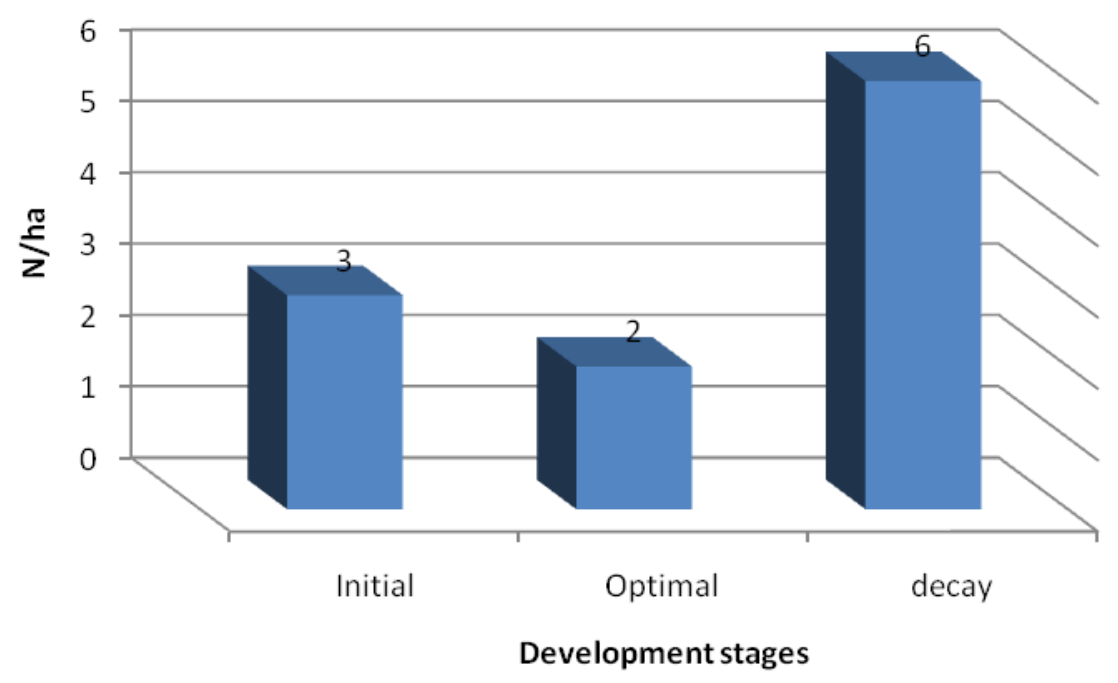

Fig.3. Average Number per Hectare of Dry and Fallen Trees According to Developmental Stages

Figure (4) shows that the standing volume has been increased in optimal stage and it has reached its minimum in decay stage. 


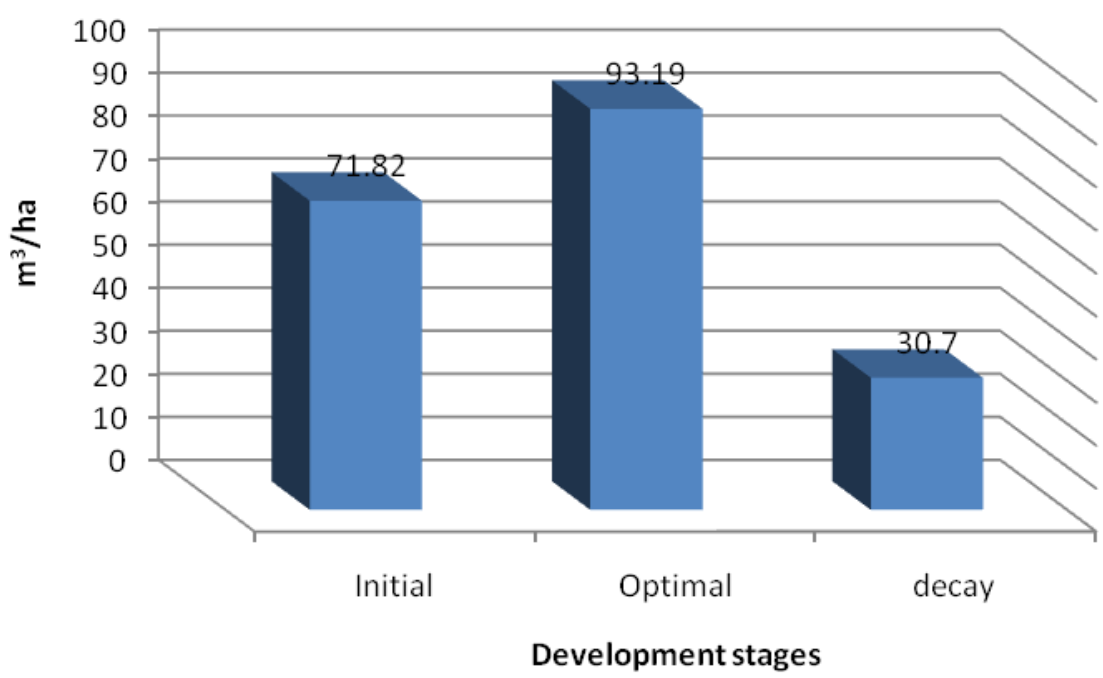

Fig.4. Average Volume per Hectare $\left(\mathrm{M}^{3}\right)$ of the Trees According to Developmental Stages

Figure (5) shows that volume of the trees has been increased in decay stage.

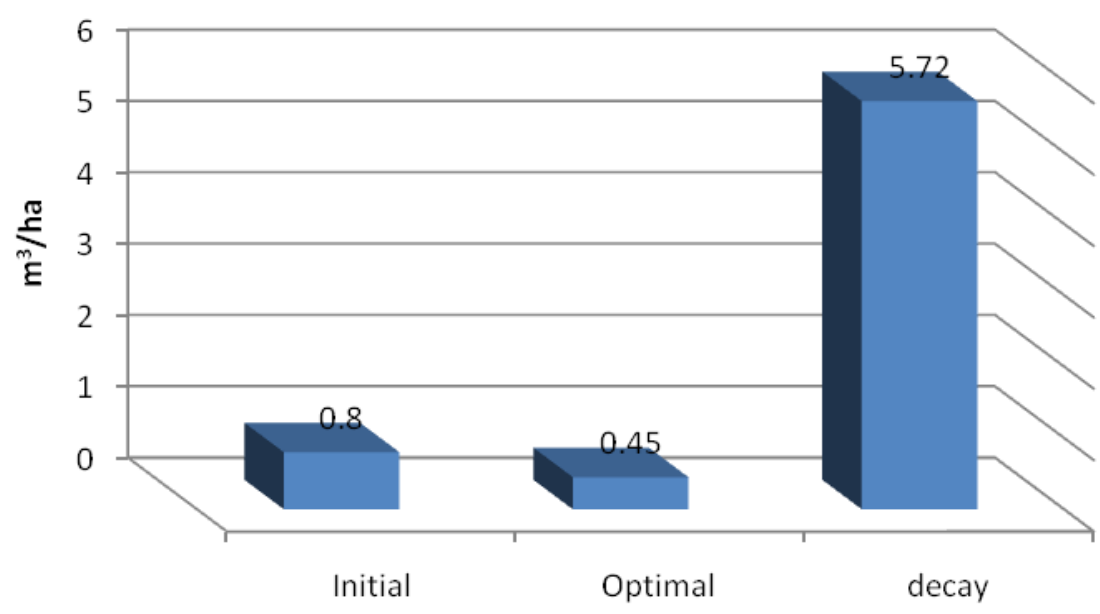

Development stages

Fig.5. Volume Average per Hectare $\left(\mathrm{M}^{3}\right)$ of Dry and Fallen Trees According to Developmental Stages

Figure 6 shows that condition of regeneration has been increased in decay stage, so that the saplings have reached the first diametrical class $\left(\mathrm{n}_{10}\right)$. 


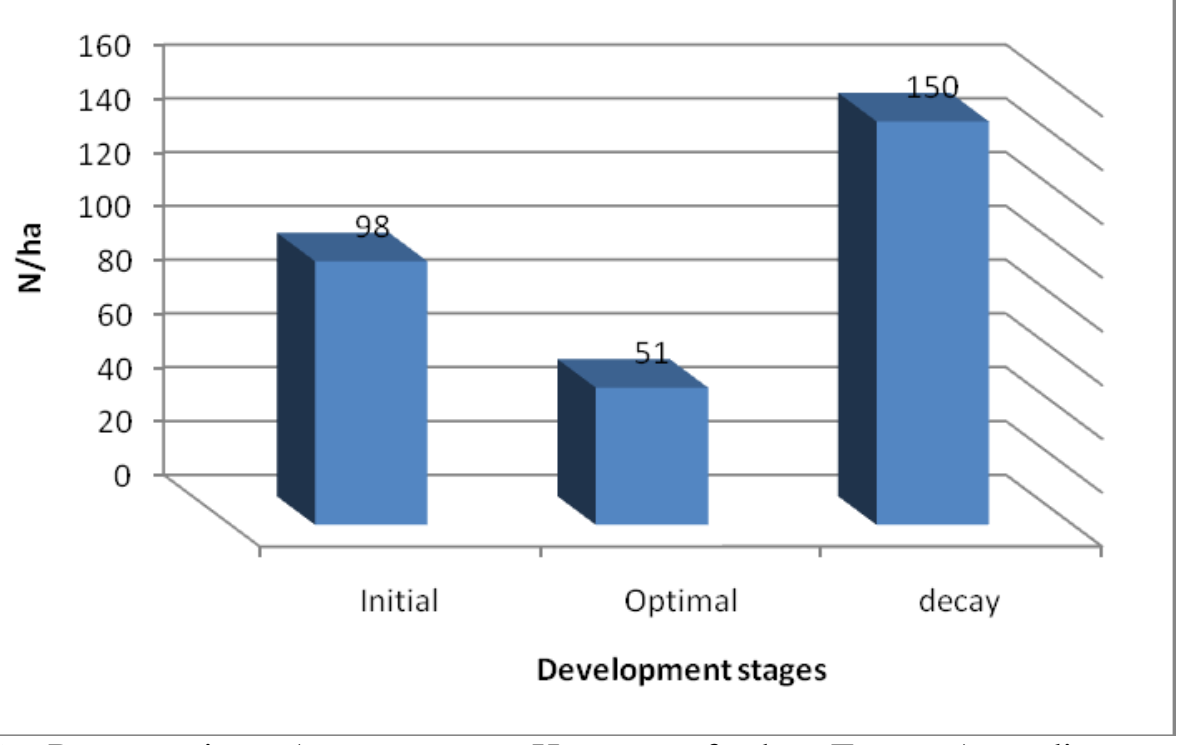

Fig.6. Regeneration Average per Hectare of the Trees According to Developmental Stages

The number per hectare of diameter classes in different developmental stage has been presented in figure7. The curve's trend is descending in the first stage and there are highest numbers of trees in diametrical classes of $(5-30 \mathrm{~cm})$, but the curve of optimal stage is bell shaped and it forms a semi even-aged stand. Although the curve of decay stage shows a descending trend, but the number of trees has had a great decrease in diameter classes of $(15-25 \mathrm{~cm})$. In primary stage, the small diameter class had the highest number that implies a young stand and the lowest number was in the large diametric class $(80<)$. But in optimal stage, the highest number exists in the middle and large diameter classes; diametric classes of $(40-70 \mathrm{~cm})$ and the lowest number exist in small and extra large diameter classes which show the high standing volume in the stand. Also, in decay stage, the highest number exists in diameter classes of $(30-40 \mathrm{~cm})$ and a descending trend was observed in diameter classes which show the low standing volume stand. Increase in number of the trees in diameter classes of $(5-15 \mathrm{~cm})$ in decay stage also, shows arrival of the regeneration into the stands.

The studies show that in terms of distribution of the trees in height classes, the curves have been bell shaped in all developmental stages. In the primary stage, the trees exist in all highest classes, but the number of trees in height classes of (25-35m) has been decreased which gaps in the stand and shows a multi-storied stand. The considerable point is that in optimal stage, highest number of the trees exist in height classes of $(25-35 \mathrm{~m})$ and number of the trees has been decreased in other height classes which shows a single storied stand; while in decay stage, number of the trees has been decreased in low height classes and it has been increased in classes of $(25-30 \mathrm{~m})$ and it has decreased again from the height of $30<$ which shows that the stand is multi-storied. 


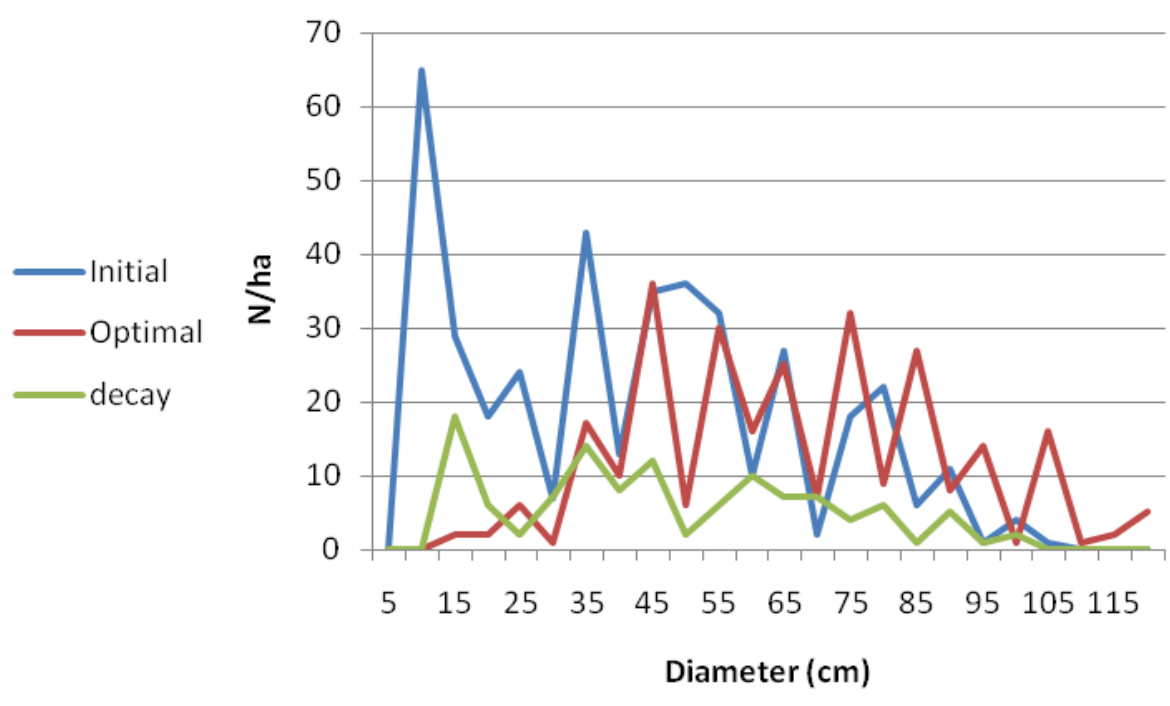

Fig.7. Average Number in Diameter Classes in Different Developmental Stages

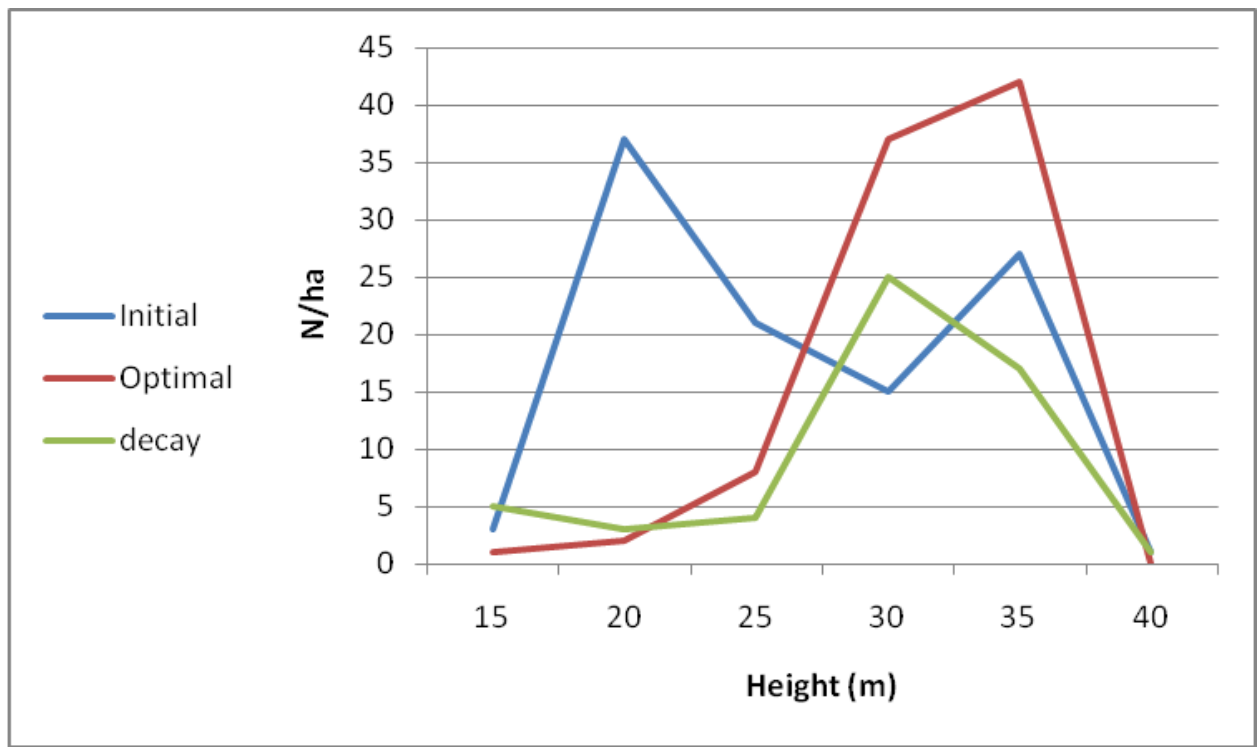

Fig.8. Average Number in height Classes in Different Developmental Stages

Figure 9 shows that quality of the tree trunk has been increased in optimal stage and decreased in decay stage. Figure 10 shows that condition ofcanopy cover in optimal stage is mainly observed in asymmetrical form and in decay stage, it is mostly symmetrical. 


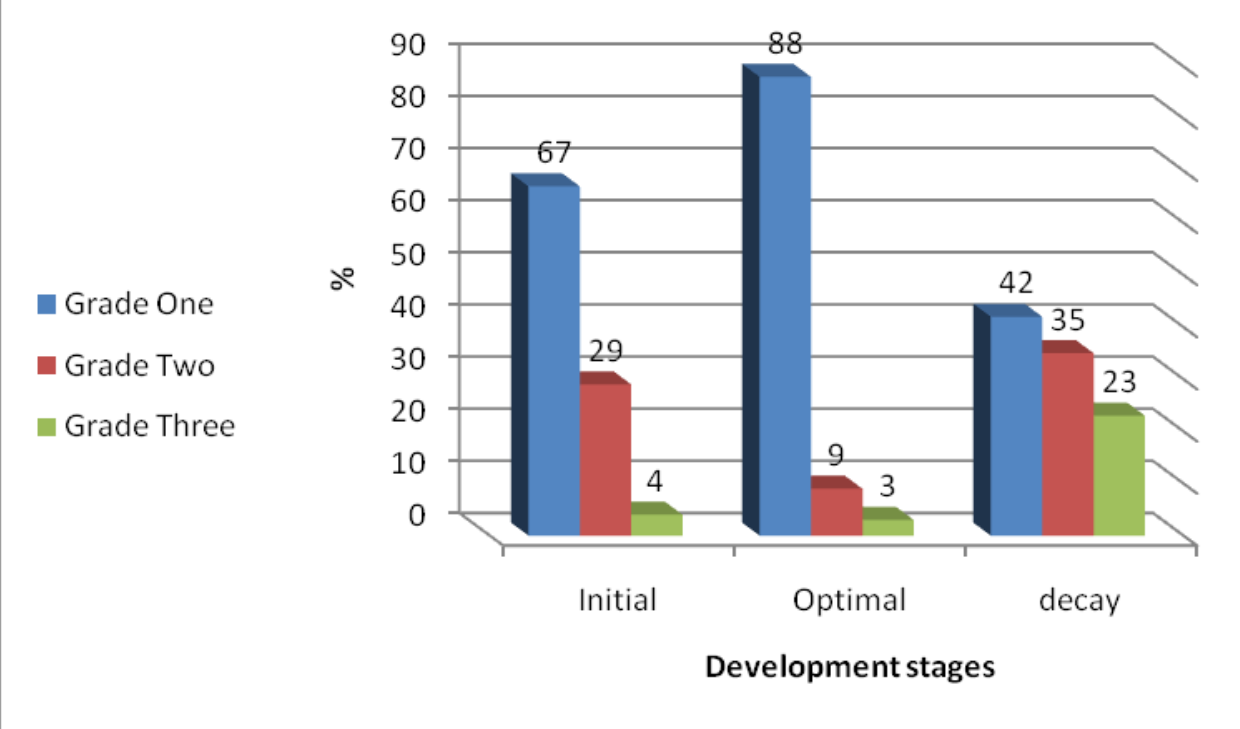

Fig.9. Quality of Tree Trunks in Different Developmental Stages

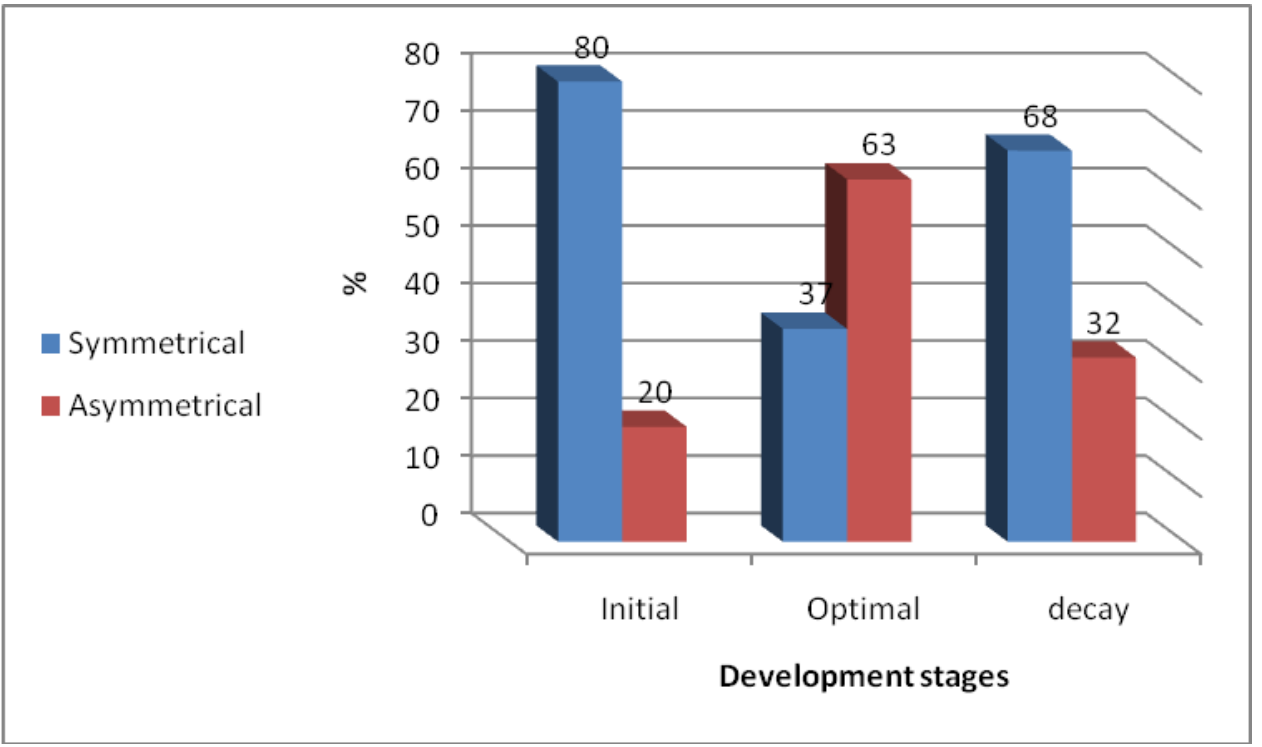

Fig.10. The Canopy Cover Condition in Different Developmental Stages

\section{DISCUSSION}

The forest communities of the northern Iran are the result of complex changes happened in natural ecosystems of these forests. Changes in natural ecosystems and particularly forests take place very slowly, in a way that they are not observable and measurable during a short period of time (Parhizkar,et al., 2011a). So difference in structure, first of all, indicates the need for steadiness and a long period of duration (Curovic, et al., 2013). The results from this study 
according to the definition presented by Korpel (1995), showed that, in terms of regeneration, average of saplings and seedlings in the micro plot has a maximum number in decay stage and a minimum number in optimal stage. Due to deletion of a large number of bases in decay stage, a relatively fewer number of trees have managed to survive. In terms of structure, in decay stage the trees are located next to each other with a lower density; for the same reason, the canopy cover is greatly reduced and several gaps are created in it. By creation of gaps in the stand, regeneration is decreased too; but in optimal stage, standing volume of the stand is high, density of the trees is more and the stand is closed in terms of canopy; therefore, there is less regeneration in the area. Parhizkar,et al (2011b) and Korpel (1995). Mataji.et al., (2014) have also concluded in their researches that among different developmental stages, decay stage had the highest and optimal stage had the lowest regenerations. Number of tree bases in the primary stage (initial) was more than climax stage and in this stage it was more than decay stage. Also, number of young trees in initial stage has been much more compared to other stages. In initial stage, the trees are placed next to each other with a higher density and the competition among them for light causes increase in diameter and height growth of the trees of the stand. And then, in optimal stage, diametric and highest growth causes canopy closure. Meanwhile, trees with small-diameters have been dried and destroyed and in decay stage, the number of tree bases has been decreased due to reaching the longevity age and deletion of a large number of bases in optimal stage and the stand canopy has been decreased.

The obtained standing volume based on the results this study was show, the from number and diameter of the tree bases in different developmental stages is high in optimal stage and low in decay stage that the results presented by Korpel (1995) also confirm the above results.

In the studies carried out in terms of quality tree trunks, it was found that the trees with good quality and first grade trunks are more but in the initial stage, considering the large number of trees with first grade tree trunks, the trees with second and third grade trunks remained from the decay stage, include a considerable portion $\% 33$ that by movement of the stand toward optimal stage, trees with second and third grade qualities are decreasing. In optimal stage, due to competition of the trees for light, the tree trunk is observed in a cylindrical and flat form and dichotomy of the trees is less. In decay stage, since the trees have reached the longevity age and also, due to pests and diseases, only \%42 of the trees have single and healthy trunks. The rest are affected by dichotomy or diseases and being turned into snags. These results are consistent with the results obtained by Alidadi (2013). In terms of canopy condition, in optimal stage, $\% 63$ are asymmetrical and $\% 37$ are symmetrical which it has a direct relationship with density of the stand. In decay stage, by opening of the canopy cover and creation of gaps, qualities of the tree canopies have been symmetrically increased. In the first stage (initial), despite the fact that $\% 68$ of canopy cover is symmetrical, the asymmetrical canopy cover is also increasing due to increase in density of the 
trees and the stand. The results from this research are consistent with the results obtained from the studies carried out by Oliver and Larson (1996).

\section{CONCLUSIONS}

According to overall results of this research, abundance of the trees in the initial stage has been decreased compared to optimal and decay stages. The highest volume has been in optimal stage and the lowest has been in decay stage. The important point is that it is not easy to separate different phases easily and it requires drawing a curve of the distribution diameter classes in a stable stand and the curve of the studied stand also, having enough experience. Therefore, the developmental phases are determined in certain scales based on management and silvicultural methods. Analysis of these phases, as a pattern of what happens in nature, can guide us in doing educational interventions and leading the stands by using close to nature silviculture method.

\section{ACKNOWLEDGEMENTS}

Financial support by Rasht Branch, Islamic Azad University Grant No. 4.5830 is gratefully acknowledged.

\section{REFERENCES}

Akhavan, R., Sagheb-Talebi, KH.,Hassani, M. and Parhizkar, P., 2010. Spatial patterns in untouched beech (FagusorientalisLipsky) stands over forest development stages in Kelardasht region of Iran.Iranian Journal of Forest and Poplar Research,18(2): 322-336.(In Persian).

Alidadi, F. 2013. Decay dynamic of beech and hornbeam dead trees in the kheiroud Forests. M.Sc. thesis, University of Tehran, 95p .

Alijani, V., Feghhi, J. and MarviMohadjer, M.R., 2012. Investigation on the beech and oak spatial structure in a mixed forest (Case study: Gorazbondistrict, Kheirud forest). Journal of Wood \& Forest Science and Technology, 19(3): 175-188p.

Curovic, M., Spalevic, V. and Medarevic M., 2013. The ratio between the real and theoretically normal number of trees in mixed fir, beech and spruce forests in the National park "Biogradska Gora". Agriculture \& Forestry, 59(1), p:7-17

Delfan Abazari, B., Sagheb-Talebi, Kh. And Namiranian, M. 2007. Regeneration gaps and quantitative characteristics of seedlings in different development stages of undisturbed beech stands (Kelardasht, Northern Iran). Iranian Journal of Forest and Poplar Research, 12(2): 302-306p .

Emborg,J.,Christensen,M. and Heilmann-Clusen,J.,2000. The structural dynamics of suserupskov, a near natural temperate deciduous forest in Denmark.Forest Ecology and Management.126:173-189p.

Eslami, A., and Kh. SaghebTalebi. 2007. Investigation on the structure of pure and mixed beech forests in north of Iran; Neka- ZaLemrud region, Pajouhesh\&Sazandegi 77: 39-46p.

Gadow, K.V., 2006. Forsteinrichtung, AdaptiveSteuerungundMehrpfadprinzip.University of Göttingen, $163 \mathrm{p}$. 
Hassani,M. Amani, M. 2009. Investigation on some qualitative and quantitative characteristics of oriental beech in the optimal phase; Sangdeh, Caspian forests of Iran, Iranian Journal of Forest and Poplar Research, 37: 4-27p.

Korpel ,Stefan , 1995 ; Die unwalder der westarpaten , GustarFischervelay , stattgart , 310.P

Leibundgut, Hans , 1993; EuropaiscbeurwalderHauptvelay, Berm ,260p.

Mataji , A. K. Sagheb-Talebi J. Eshaghi-Rad.2014. Deadwood assessment in different developmental stages of beech (Fagus orientalis Lipsky) stands in Caspian forest ecosystems. Int. J. Environ. Sci. Technol. 11(5):1215-1222p.

Motz, K., Sterba, H. and Pommerening, A., 2010. Sampling measures of tree diversity. Forest Ecology and Management, 260: 1985-1996p.

Oliver, C.D. and Larson, B.C. 1996. Forest Stand Dynamics. Wiley, New York, 520p.

Parhizkar, P., Kh. Sagheb-Talebi2, A. Mataji1 and M. Namiranian3.2011b. Influence of gap size and development stages on the silvicultural characteristics of oriental beech (Fagus orientalis Lipsky) regeneration. Caspian J. Env. Sci., 9 (1) :55-65p.

Parhizkar, P., Sagheb-Talebi, Kh.,Mataji, A., Nyland, R. and Namiranian, M. 2011a.Silvicultural characteristics of oriental beech (FagusorientalisLipsky) regeneration under different RLI and positions within gaps. Forestry, 84: 177$185 \mathrm{p}$.

Sagheb-Talebi Kh, Delfan Abazari B, Namiranian M (2003) Description of the decay stage in a natural oriental beech (Fagus orientalis Lipsky) forest in Iran. Proceedings of IUFRO international conference, Mukachevo, Ukraine, 13-17 October 2003, 130-134 p.

Sefidi, K. and Marvie-Mohadjer, M.R. 2010.Characteristics of coarse woody debris in successional stages of natural beech (Fagusorientalis) forests of Northern Iran. Journal of Forest Science, 56: 7-17p.

Sefidi,K. M.R. Marvie Mohadjer, V. Etemad and R. Mosandl. 2014. Late successional stage dynamics in natural Oriental beech (Fagus orientalis Lipsky) stands in northern Iran (Case study: Gorazbon district of Kheiroud-Kenar experimental forest). Iranian Journal of Forest and Poplar Research .22 (2): 270-283p. 